\title{
BRASIL E ARGENTINA EM PERSPECTIVA
}

\author{
Leonel Itaussu Almeida Mello
}

Titular em Ciência Política - FFLCH/USP

\section{Resumo}

Esse artigo analisa as relações entre Brasil e Argentina dentro de uma perspectiva histórica de síntese, que se estende do século XVII ao XX. A característica estrutural desse relacionamento é o processo pendular que oscila do conflito à cooperação entre as duas potências da Bacia do Prata.

\section{Abstract}

This article analyses the relationship between Brazil and Argentina, considering a synthetic historical perspective - from XVII ${ }^{\text {th }}$ to $\mathrm{XX}^{\text {th }}$ centuries - as background. The main structural feature of this relationship is the pendular process which goes from conflict to cooperation between these two great nations in the La Plata Basin.

\section{Pallavras-Chave}

Argentina-Brasil • Competição • Cooperação • Integração

\section{Keywords}

Argentina-Brazil • Competition • Cooperation • Integration 
0

cenário que emoldura o tema deste artigo é a América do Sul, subcontinente que, na síntese lapidar de Lewis Tambs, "cercado por três mares - o Atlântico, o Pacífico e o Caribe; equilibrado por três altiplanos - o Andino, o Brasileiro e o Guiano; e atravessado por três rios - o Prata, o Amazonas e o Orenoco, inclina-se para o Altântico" (Tambs 1983: 90-91). Em termos de delimitação espacial, essa massa geográfica meridional compartimenta-se em três grandes regiões geopolíticas: a amazônica, a andina e a platina. Esta última, com seus 3,5 milhões de $\mathrm{km}^{2}$ e 100 milhões de habitantes, assemelha-se a um triângulo invertido com seus vértices em Sucre, Santos e Buenos Aires, e uma extensa fachada atlântica que se estende do litoral sul brasileiro até o delta platino.

Nos pontos extremos do sistema fluvial platino situam-se os dois maiores centros econômicos e demográficos sul-americanos: São Paulo, no planalto de Piratininga e Buenos Aires, na planície pampeana. Dentro do triângulo platino existem dois grandes eixos populacionais: o argentino-uruguaio, no sentido oeste-leste, formado por Rosário, Buenos Aires e Montevidéu; e o brasileiro, no sentido sudeste-nordeste, formado por Porto Alegre, Curitiba e São Paulo (Aicardi s.d.: 31-42). Os principais rios da bacia platina - Paraná, Paraguai, Uruguai e Prata - e os territórios adjacentes constituem parte integrante do nosso tema de reflexão: o relacionamento brasileiro-argentino.

Embora bastante valorizado nos últimos anos, o estudo das relações entabuladas entre o Brasil e a Argentina não deve ser encarado como um subproduto do Acordo, da Ata de Integração e do conjunto de Protocolos abrangendo um amplo e diversificado espectro de temas políticos, militares, econômicos, tecnológicos e culturais, assinados há quinze anos (1986). Ao contrário, o exame da literatura disponível demonstra que a relevância e a atualidade do intrincado relacionamento brasileiro-argentino têm sido destacadas, implícita ou explicitamente, em publicações antigas ou recentes, por vários intelectuais de renome internacional e de reconhecida autoridade acadêmica.

Em um ensaio clássico, datado de 1933, Caio Prado Jr. salientava que o assunto enfocado - o processo de fixação das linhas demarcatórias brasileiras na Bacia do Prata - não era um mero exercício de bizantinismo histórico, mas uma questão da maior centralidade nas relações internacionais dos Estados sul-americanos, à qual 
se ligavam "alguns dos acontecimentos mais salientes da história, tanto do Brasil como das repúblicas platinas". Acrescentava ainda o citado historiador que, ao evidenciar a interação recíproca de fatores geográficos e históricos, o assunto relativo à formação dos limites meridionais brasileiros era particularmente propício ao enfoque de uma disciplina sociológica recém-formada, a geopolítica, desde que usada cum grano salis: "geopolítica no bom sentido; ciência, e não pretexto e arma ideológica de pretensões internacionais descabidas e agressões injustificáveis” (Prado Jr. 1972:143).

Em livro de publicação mais recente, no qual analisa as relações de conflito/cooperação brasileiro-argentinas, Hélio Jaguaribe enfatiza também o papel dos condicionamentos histórico-geográficos no processo de interação entre os dois países, afirmando inclusive que a importância da fronteira sulina resulta não de sua extensão, mas fundamentalmente do fato de ter sido, desde a época colonial, "a zona de encontro e de tensão entre os sistemas português e espanhol” (Jaguaribe 1986:165).

As referências acima, que à primeira vista poderiam ser tomadas como argumento de autoridade, ganham maior consistência quando corroboradas por uma série de dados que evidenciam o peso relativo de ambos os países no conjunto da América Latina.

Algumas estatísticas agregadas, relativas ao ano de 1999, demonstram que Brasil e Argentina possuem conjuntamente uma área de 11,8 milhões de $\mathrm{km}^{2}$, uma população de 200 milhões de pessoas e um produto bruto de US\$ 1 trilhão, representando, aproximadamente, metade do território, dos habitantes e do PIB total da América Latina. Ambos os países possuem o maior e o mais diversificado parque industrial ao sul do Rio Grande, complementado por imensas fontes de energia, ferro, manganês, urânio, carnes e cereais, além de ocuparem uma posição geoestratégica essencial à defesa e à segurança do Atlântico Sul.

Ademais de sua notória e evidente atualidade, a relevância do relacionamento Brasil-Argentina e da interação de ambos com os demais países platinos - Uruguai, Paraguai e Bolívia - pode ser igualmente demonstrada mediante análise das vicissitudes do passado comum à guisa de um breve balanço retrospectivo.

Os conflitos luso-espanhóis durante o período colonial e a rivalidade brasileiroargentina após a independência íbero-americana constituíram-se historicamente no 
epicentro das constantes oscilações geopolíticas ocorridas na região platina. De todas as regiões latino-americanas, a Bacia do Prata foi aquela que se transformou no palco dos mais numerosos e cruentos conflitos bélicos travados entre os Estados do subcontinente desde a emancipação política: as guerras da Cisplatina, do Paraguai e do Chaco. Ademais, há que se recordar também que, à exceção do Brasil com a Bolívia, todos os outros países platinos empreenderam guerras entre si.

A "questão platina" tornou-se o fulcro da rivalidade hispano-lusitana no Novo Mundo desde 1680, com a fundação da Colônia do Sacramento à margem esquerda do rio da Prata, praticamente defronte a Buenos Aires. Essa fortificação foi erigida como um posto militar avançado para assegurar à Coroa portuguesa uma "fronteira natural" entre seus domínios e os de Espanha ao sul do continente, assim como o livre acesso à navegação e ao comércio platinos, consoante o princípio geopolítico de que o poder que dominar a desembocadura controlará o rio.

A edificação do forte inseriu-se no contexto do recrudescimento da rivalidade luso-castelhana após o interregno de mais de meio século de união das Coroas ibéricas (1580-1640). Após a Restauração portuguesa intensificou-se o processo de expansão bandeirante-vicentina por territórios espanhóis situados além da linha de Tordesilhas, reacendendo o choque entre as metrópoles ibéricas na América colonial. Em meados do século XVIII, o Tratado de Madri, com base no princípio do uti possidetis (posse pela ocupação), transferiu aos portugueses o domínio de um vasto território americano que, nos termos do acordo de Tordesilhas, constituía de direito possessão da Coroa espanhola. Com isso consumou-se a "marcha para o Oeste", que agregou uma nova área de 5 milhões de $\mathrm{km}^{2}$ aos 2,8 milhões de $\mathrm{km}^{2}$ que formavam originalmente o império luso-americano.

Francisco de Auzmendi, oficial-maior da Secretaria dos Negócios Estrangeiros da Espanha àquela época, emitiu um juízo sobre o acordo luso-castelhano que merece ser reproduzido pela argúcia com que capta e sintetiza o espírito do Tratado de Madri segundo a ótica dos interesses espanhóis: "A substância do Tratado consiste em concessões mútuas e na partilha de um imenso território despovoado. Nós cedemos a Por- 
tugal o que não nos serve e para eles será de grande utilidade; e Portugal nos cede a Colônia e o rio da Prata que não os beneficia e nos destrói” (apud Soares 1972:32-3).

Destarte, a Espanha reconheceu a Portugal a posse da Bacia Amazônica em troca do controle da Bacia do Prata, onde os portugueses receberam os Sete Povos das Missões como compensação pela transferência aos espanhóis da Colônia do Sacramento e da margem esquerda do rio da Prata. Com esta permuta Portugal apossou-se de terras no interior do que seria futuramente o Rio Grande do Sul e abdicou ao estuário platino como fronteira meridional de seu império americano. Para precaver-se contra um novo surto expansionista luso-brasileiro na direção sudoeste-sul, a Espanha criou em 1763 o Vice-Reinado do Rio da Prata, englobando a Argentina, a Banda Oriental (futuro Uruguai), o Paraguai e o Alto Peru (futura Bolívia), com capital em Buenos Aires.

O Virreinato possuía uma área de 5 milhões de $\mathrm{km}^{2}$ e 1 milhão de habitantes, constituindo um corpo político-administrativo em condições de opor uma barreira de contenção às pretensões portuguesas na Bacia do Prata. A renúncia à "fronteira natural" dos domínios lusitanos meridionais transformou-se durante o século XIX no nó górdio ou no gargalo das tensas e complexas relações de vizinhança entabuladas pelos Estados nascentes que partilhavam em regime de condomínio o sistema fluvial platino.

Com a emancipação latino-americana, o descompasso que caracterizou os processos de desenvolvimento das duas potências platinas jogou enorme papel na desconfiança e na ambivalência que estigmatizaram desde o início o relacionamento entre o Brasil e a Argentina.

Em 1808, a transformação do Brasil em sede da Coroa portuguesa, com a vinda da família real, da corte bragantina, da burocracia civil-militar e a transferência do aparelho administrativo estatal metropolitano para a colônia, contribuíram para que o país realizasse a independência por meio de um "arranjo político" ou de uma "negociação pelo alto" entre o príncipe regente português (D. Pedro) e a oligarquia agrária-escravocrata nativa (o "partido brasileiro"). Ao cimentar a aliança entre a dinastia Bragança e os grandes proprietários rurais, a solução monárquica logrou 
exorcizar o fantasma da anarquia interna, preservando intacta a unidade política e a integridade territorial do Império recém-fundado.

Destino diverso coube ao Vice-Reinado do Prata, onde a independência realizouse pela via republicana e desembocou num processo duplamente conturbado. Inicialmente, ocorreu a secessão das regiões periféricas do Virreinato, cuja balcanização separou a Banda Oriental, o Paraguai e o Alto Peru do território argentino, ficando este último reduzido a uma área de 2,7 milhões de $\mathrm{km}^{2}$. Em seguida, a própria Argentina foi engolfada em meio século de guerras civis entre a oligarquia litorânea (unitários) e os caudilhos do interior (federalistas), que somente terminou em 1880 com a vitória de Buenos Aires sobre as províncias.

Após o triunfo de portenhos sobre arribenhos, o país viveu um surto de prosperidade econômica que se estendeu até a Primeira Grande Guerra. Entre 1886 e 1914 o PIB argentino saltou de US\$ 1 bilhão para US\$ 15 bilhões, sendo que às vésperas da Primeira Guerra o país era responsável pela metade da capacidade econômica e pela terça parte do comércio exterior de toda a América Latina (Bandeira 1987:16; Schilling 1990:34). Nos quinze primeiros anos deste século a Argentina triplicou sua área cultivada, passando de 6,1 milhões de hectares para 21,3 milhões de hectares (Bandeira 1987:16), e, de produtora de couros no período colonial, transformou-se "em imensa fábrica de carne e numa grande usina de trigo" que abasteciam o mercado britânico (Chaunu 1971:91).

Referindo-se ao boom argentino da virada do século, Celso Furtado afirma que, entre 1890-1914, a população do país duplicou, saltando de 3,6 milhões para 7,2 milhões; a rede ferroviária cresceu de 12,7 mil km para 31,1 mil km; as exportações de cereais saltaram de 1.038 para 5.294 milhares de toneladas e as de carnes congeladas de 27 para 376 mil toneladas (Furtado 1969:67).

Cristalizou-se naquela época a concepção de uma Argentina-insular, que voltava as costas às províncias do interior e aos países sul-americanos ao mesmo tempo em que se debruçava sobre o litoral e se abria para o exterior. O projeto liberal-conservador da "geração de 80" estruturou um modelo de desenvolvimento dependente voltado para o mercado externo, com uma economia agropastoril centrada espacial 
e demograficamente no Pampa Húmeda e no porto de Buenos Aires, relegando ao abandono a Mesopotâmia e a Patagônia.

A concepção geopolítica da insularidade tinha como paradigma a Grã-Bretanha e foi sistematizada pelo almirante Segundo R. Storni, cujo livro Interesses argentinos en el mar, publicado em 1916, inspirou-se nas idéias do almirante norte-americano Alfred T. Mahan e do geógrafo alemão Friedrich Ratzel.

O modelo de inserção subalterna e especializada na divisão internacional do trabalho, onde a Argentina desempenhava o papel de granja ou celeiro que, em troca de manufaturas, abastecia a Europa de alimentos, só revelou os primeiros sintomas de esgotamento a partir do crack de 1929. Para se ter uma idéia da prosperidade portenha basta apenas assinalar que, às vésperas da Grande Depressão, o PIB argentino era o dobro do PIB brasileiro e equivalente ao produto bruto somado de todos os países sul-americanos (Boscovich 1983:96).

Contrastando com a prosperidade argentina, o final do século passado foi para o Brasil um período de recessão e instabilidade em que se acoplaram a crise econômico-financeira, que se agravou com o término da Guerra do Paraguai, e a crise político-institucional da monarquia, abalada pelas questões servil, religiosa e militar. Em 1889, ambas as crises desembocaram no golpe que promoveu a substituição do Império pela República.

Após o curto interregno de jacobinismo militar, a República nascente adotou também um modelo político e econômico liberal que, em suas linhas gerais, perdurou até a Revolução de 1930. Vale lembrar que os pilares do liberalismo de tipo excludente eram a supremacia política das oligarquias rurais, assegurada pelo coronelismo, a política dos governadores e o predomínio dos grandes estados; a economia dependente primário-exportadora, centrada na cafeicultura, oficializada pelo Convênio de Taubaté e sustentada pela política de valorização do produto-rei; e a política de desvalorização cambial, cujo ônus financeiro era repassado à sociedade por meio do mecanismo de "socialização das perdas".

A Grande Depressão revelou a fragilidade e os limites do liberalismo de corte oligárquico tanto na Argentina como no Brasil, cujas economias reagiram diversamente à crise do modelo primário-exportador. No Brasil, a reação ao colapso da 
monocultura cafeeira demonstrou, a partir da Revolução de 30, as virtualidades da política de industrialização via substituição de importações. Na Argentina, a anarquia da "década infame" assinalou o fim da "época de ouro"; o malogro relativo de uma tentativa industrializante similar à brasileira contribuiu para perpetuar o decadente modelo agro-pastoril eurocêntrico, baseado no ultrapassado liberalismo oitocentista.

A Segunda Guerra Mundial reativou temporariamente a prosperidade argentina com o aumento da demanda externa sobre seus principais produtos de exportação: a carne e o trigo. As reservas monetárias acumuladas durante o conflito financiaram no pós-guerra o processo de modernização sócio-econômica promovido por Perón por meio de uma política baseada em três pilares: a industrialização substitutiva; o nacionalismo populista; e o redistributivismo social.

A equiparação do produto interno dos dois países no final da década de 1950 serviu para evidenciar tanto o dinamismo do modelo brasileiro quanto o esgotamento do modelo argentino. Nas décadas subseqüentes configurou-se a seguinte situação: em 1970 o PIB argentino representava perto de dois terços do PIB brasileiro, caindo para um terço em 1980 e para pouco mais de um quarto em 1985 (Cepal 1987:14647). Resumindo: em 1930 a economia argentina era o dobro da brasileira e meio século depois a economia brasileira tornara-se o quádruplo da argentina, na última década, porém, essa diferença caiu para menos de um terço.

No âmbito das relações internacionais, a decadência das respectivas metrópoles no século XVIII deslocou o Brasil e a Argentina para a esfera de influência britânica. Após a emancipação latino-americana no século seguinte, a Grã-Bretanha tornouse o fiel da balança de poder platina e praticou em relação àqueles países uma política de equilíbrio que assegurou o predomínio dos seus interesses na Bacia do Prata.

Exemplo de tal política foi a independência da Banda Oriental, anexada ao Brasil em 1821 sob a denominação de Província da Cisplatina. A luta dos patriotas orientais contra o Império foi apoiada pelas Províncias Unidas, que almejavam o controle de ambas as margens do Prata pela anexação do território vizinho. A intervenção argentina desencadeou a Guerra Cisplatina, que terminou em 1828 com a mediação inglesa. Esta procurou assegurar seus interesses no Prata ao apoiar a independência 
do Uruguai, um Estado-tampão (buffer state) destinado a amortizar a rivalidade entre o Império bragantino e a República portenha, impedindo que qualquer deles controlasse monopolisticamente a desembocadura e o comércio platinos. Lorde Ponsomby, o mediador da paz, sintetizou o papel desempenhado pelos britânicos numa frase lapidar: "colocamos um algodão entre dois cristais".

Em meados do século XIX, a Grã-Bretanha superava os Estados Unidos no comércio com as jovens repúblicas hispano-americanas na base de US\$ 60 milhões contra US \$ 24 milhões, enquanto nas trocas com o Brasil a proporção era de US\$ 20 milhões para a primeira contra US\$ 4,2 milhões para o segundo. Às vésperas da Primeira Guerra, os investimentos britânicos na Argentina atingiam $£$ 319,6 milhões (contra $£$ 148 milhões aplicados no Brasil), montante que se aproximava dos $£ 378,8$ milhões investidos pela Grã-Bretanha na Índia e no Ceilão (Chaunu 1971:108-14). Estas cifras demonstram que, desde a independência, tanto o Brasil como a Argentina encontravamse inseridos no espaço geopolítico de influência da hegemonia britânica.

No começo do século XX, com suas ferrovias e frigoríficos controlados por capitais ingleses, que representavam $80 \%$ dos investimentos estrangeiros, a Argentina era considerada uma semicolônia ou o "sexto domínio" do Império Britânico. Enquanto a oligarquia argentina mantinha-se aferrada à sua “vocação européia", com a Grã-Bretanha importando 76\% de sua carne e 34\% de seu trigo (Bandeira 1987:15), a diplomacia do barão do Rio Branco reorientou a inserção do Brasil no cenário internacional, deslocandoo paulatinamente para a esfera de influência dos Estados Unidos.

A nova entente brasileiro-norte-americana foi determinada, por um lado, pelo receio de uma coalizão antibrasileira dos países hispânicos sob a liderança de um Estado-monitor argentino e, por outro lado, pela necessidade de contrabalançar o peso excessivo da influência britânica na América do Sul. Além da especificidade da disputa pela supremacia platina, a rivalidade brasileiro-argentina da primeira metade do século XX entrelaçou-se também no mesmo período com a rivalidade anglo-norte-americana pela hegemonia na América do Sul.

Em 1913, os investimentos norte-americanos na América Latina somavam US\$ 1,250 bilhão (dos quais US\$ 1,050 aplicado no México) contra US\$ 4 bilhões da 
Grã-Bretanha. Por volta de 1929, o montante das inversões norte-americanas ascendera a US\$ 4,050 bilhões, equiparando-se aos investimentos ingleses. No volume total de troca com os países latino-americanos, os norte-americanos superavam os britânicos na razão de 38,7\% contra 14,9\% nas exportações e de 34\% contra $18 \%$ nas importações (Chaunu 1971:118-19).

No âmbito das relações bilaterais, cada país produziu de si uma auto-imagem idealizada e construiu do outro uma visão preconceituosa, ambas refletindo parcialmente o descompasso existente entre os processos de desenvolvimento brasileiro e argentino. Na percepção argentina, o Brasil era portador de uma irrefreável vocação expansionista, herdada do "espírito bandeirante" e da geofagia lusitana; na percepção brasileira, a Argentina acalentava um ethos irredentista, cujo sonho era a restauração do antigo Vice-Reino do Prata hegemonizado por Buenos Aires. Alimentado por esses estereótipos, desde o início do século XIX o relacionamento entre os dois países oscilou pendularmente entre o conflito e a cooperação.

Durante a guerra fria dos anos 50, simultaneamente ao recrudescimento da tensão entre os vizinhos platinos, o general Golbery do Couto e Silva alardeava em seus escritos geopolíticos a inserção do Brasil no mundo ocidental-cristão e seu alinhamento pró-norte-americano no antagonismo dominante Leste-Oeste. Confrontando a política de Terceira Posição do peronismo argentino, Golbery propunha a Washington uma "barganha leal": o Brasil assumiria uma posição de alinhamento estratégico aos Estados Unidos no conflito Leste-Oeste e, em troca, teria reconhecido o seu suposto direito a um “destino manifesto" no Atlântico Sul (Couto e Silva 1967:50-2).

O clima de animosidade predominante entre os dois países platinos materializava-se na tensão fronteiriça que se tomava crescente com o deslocamento da linha divisória de oeste para sul, refletindo a colisão dos interesses brasileiro-argentinos em sua luta pela preponderância nos países mediterrâneos platinos: "Mais ou menos tributários da Argentina, oscilando entre a desconfiança, o ressentimento e a admiração e jungidos pela dependência econômica indiscutivel - o Paraguai e a Bolívia, "prisioneiros geopolíticos", muito mais o primeiro que a segunda, valem muito pela sua posição geográfica no flanco aberto e vulnerável do Brasil meridional 
e central e constituem, sobretudo por sua instabilidade política e econômica, indisfarçáveis zonas de fricção externa onde podem vir a contender, quer queiram. quer não, os interesses brasileiros e argentinos” (Couto e Silva 1967:55).

A tensão ascendente atingia seu limiar na fronteira extremo-meridional, onde se chocaram no passado as forças luso-castelhanas e colidiam no presente as pretensões brasileiro-argentinas. Segundo o autor, essa área constituía "zona de vulnerabilidade máxima" exposta a ações adversas de origem regional. A citação abaixo é emblemática do ethos conflitivo e da percepção ideológica deformante que, atenuados por hiatos de cooperação, iriam ressurgir na década de 70, quando a desconfiança recíproca voltou a ser a nota dominante do discurso de setores civis e militares de ambos os países: "Mas é bem mais ao sul, onde o Uruguai, geograficamente meio brasileiro e meio platino, continua a viver e prosperar galhardamente em seu histórico papel de Estado-tampão, é aí onde Las Missiones avançam como uma cunha para o nordeste modelando o gargalo de Santa Catarina, que se define a linha de tensão máxima do campo sul-americano, reforçada como é pela proximidade maior dos centros de força potencialmente antagônicos, seu dinamismo e potencial superiores, a tradição de choques e conflitos que vêm desde o passado colonial e, por fim, se bem não menos importante, uma aspiração hegemônica alimentada além do Prata por uma propaganda tenaz e incansável desde os dias já longínquos de Rosas. Aí, onde não há barreiras que valham, se encontra pois nossa verdadeira fronteira viva (...)" (Couto e Silva 1967:58).

Por sua vez, o clima de confrontação dos anos setenta, centrado na polêmica questão de Itaipu, cederia lugar na década de noventa a uma nova fase de cooperação entre os dois países. Ao longo dessas três décadas as relações bilaterais brasileiroargentinas passaram por três etapas sucessivas: competição, distensão e integração. Os anos de 1973, 1979 e 1986 sinalizam cronologicamente os eventos político-diplomáticos que, analisados retrospectivamentte, destacam-se como os principais momentos de inflexão de cada umas das mencionadas etapas: o Tratado de Itaipu, o Acordo Tripartite e a Ata de Integração. 
Em 1973, as relações brasileiro-argentinas entraram numa dinâmica de aberta competição, e isto em razão da assinatura do Tratado de Itaipu com o Paraguai, Estado amortizador das tensões entre os dois grandes vizinhos e país mediterrâneo geoestrategicamente situado a cavaleiro do sistema fluvial platino. A rigor, as divergências bilaterais vinham se agravando veladamente desde 1971, quando a política brasileira de "fronteiras ideológicas" entrou em rota de colisão com a diplomacia argentina de "convivência no pluralismo ideológico", colocada em prática pelo governo Lanusse com o escopo de contrabalançar a projeção do Brasil no subcontinente. A construção de uma gigantesca usina binacional a 17 quilômetros da fronteira argentina e o risco de um completo alinhamento paraguaio à política brasileira, vistos por Buenos Aires como uma séria ameaça ao equilíbrio geopolítico platino, transformaram-se no pomo de discórdia da rivalidade entre ambos os países durante a década de 1970.

Em 1979, a negociação de um Acordo Tripartite (assinado também pelo Paraguai) compatibilizou tecnicamente as usinas de Itaipu e Corpus, situadas a montante a a jusante do rio Paraná, abrindo-se assim uma nova fase de distensão das relações brasileiro-argentinas. Ao solucionar o conflito diplomático-geopolítico na região platina e ao assegurar o espaço necessário à manutenção da tradicional pendularidade paraguaia, a solução da denominada "questão de Itaipu" propiciou a normalização do relacionamento brasileiro-argentino e a retomada da cooperação bilateral no começo da década de 1980.

Em 1986, a assinatura da Ata e dos Protocolos oficializou o projeto de integração econômica bilateral e de cooperação multissetorial, a ser viabilizado de forma gradual, equilibrada e mutuamente vantajosa. Ao lado do desenvolvimento econômico e da modernização científica e tecnológica, outra importante dimensão do projeto integracionista foi o compromisso político assumido pelos novos sócios com a consolidação do recém-instaurado regime democrático. A partir daí, a implementação do processo de integração bilateral delineou a matriz original que, com a adesão do Uruguai e a democratização do Paraguai, serviu de arcabouço à proposta de criação de um mercado comum dos países do Cone Sul - o Mercosul -, sacramentada no começo de 1991 com a assinatura do Tratado de Assunção. 
O início do terceiro milênio prenuncia o advento de um novo sistema internacional, ainda bastante híbrido, denominado de "unimultipolar" por Samuel Huntington. As principais características desse novo sistema são, simultaneamente, a unipolaridade estratégico-militar, a multipolaridade econômico-tecnológica, a globalização e a regionalização econômicas. A “Nova Ordem Mundial” é marcada pelo fim da bipolaridade estratégico-militar Leste-Oeste em decorrência da implosão do bloco socialista e do fim da União Soviética; pela emergência de uma única hiperpotência global multidimensional (os Estados Unidos); pela crescente multipolaridade econômico-tecnológica, cujos pontos focais são os Estados Unidos, a União Européia e o Japão; pela organização dos megablocos regionais, como o norte-americano-canadense-mexicano, o europeu-ocidental e o asiático-oriental; e pelo aprofundamento da bissegmentação econômica em torno do eixo Norte-Sul, que divide o planeta em dois submundos distintos: o desenvolvido e o subdesenvolvido.

Nesse contexto, a consolidação de um espaço geoeconômico brasileiro-argentino torna-se uma questão da maior relevância, suscetível de produzir repercussões em nível platino - com a adesão do Uruguai e do Paraguai -, além um grande impacto nos países dos sistemas andino e amazônico da América do Sul. O subcontinente sul-americano possui uma área de 17 milhões de km2, habitada por 350 milhões de pessoas, com um PIB de US\$ 1,6 trilhão e US\$ 150 bilhões de exportações. Dentro desse conjunto o Mercosul forma, somados os quatro países-membros, um megabloco geo-econômico de quase 12 milhões de km2, povoado por mais de 200 milhões de habitantes, com um PIB superior a US\$ 1 trilhão, uma renda per capita de US\$ 5 mil, exportações equivalentes a US\$ 90 bilhões e importações de US\$ 100 bilhões.

Em suma, o Mercosul representa aproximadamente 2/3 do potencial global geográfico, demográfico e econômico - de toda a América do Sul. Não é pouca coisa como ponto de partida ou plataforma de decolagem. Para quem pensa como Simon Bolívar que "a pátria é a América" o Mercosul foi, ao contrário, um bom começo, a despeito das vicissitudes que no momento atingem a Argentina, do fantasma da ALCA que ronda o subcontinente meridional e da crise conjuntural que assola atualmente a união aduaneira dos países platinos. No final da década de 70 o general Guglialmelli 
predisse que "o Cone Sul poderá ser um ponto de partida para a ulterior unidade da América Latina e um núcleo de poder regional frente aos grandes centros de poder mundial'. Por sua vez, Juan Domingo Perón, que sabia das coisas da política, havia vaticinado, muito antes, que o século XXI encontraria a Argentina e o Brasil "unidos ou subjugados". O terceiro milênio está apenas começando: quem viver, verá!

\section{Referências Bibliográficas}

AICARDI, Raul Federico Abadie. Antecedentes históricos y marco geopolítico de la cuenca, Montevideo, Centro latinoamericano de Economia Humana, s.d.

BANDEIRA, Moniz. O eixo Brasil-Argentina: o processo de integração da América Latina. Brasília, Editora UNB, 1987.

BOSCOVICH, Nicolás. "La Argentina em la cuenca del Plata”. In: Los países del Atlântico Sur: Geopolítica de la Cuenca del Plata. Buenos Aires, Editorial Pleamar, 1983.

CHAUNU, Pierre. História da América Latina. São Paulo, Difusão Européia do Livro, 1971. CEPAL (Comision Economica para America Latina y el Caribe). Anuário estadístico de América Latina y el Caribe. Nova Iorque, Nações Unidas, 1987.

COUTO E SILVA, Golbery do. Geopolítica do Brasil. Rio de Janeiro, 2 edição, Livraria José Olympio Editora, 1967.

FURTADO, Celso. Formação econômica da América Latina. Rio de Jneiro, Lia Editor, 1969.

GUGLIALMELLI, Jaun Enrique. Geopolitica del Cono Sur. Buenos Aires, El Cid Editor, 1979. JAGUARIBE, Hélio. Novo Cenário Internacional. Rio de Janeiro, Editora Guanabara, 1986.

SOARES, Teixeira. História da formação das fronteiras do Brasil. Rio de Janeiro, Conselho Federal de Cultura, 1972.

SCHILLING, Paulo. "O colapso econômico da Argentina” In: Tempo e Presença, no. 250, ano 12, São Paulo, CEDI, 1990.

PRADO JR, Caio. Evolução política do Brasil e outros estudos. São Paulo, Editora Brasiliense, 8 edição, 1972.

TAMBS. Lewis."Geopolítica, política internacional e estratégia". In: Política e Estratégia, vol. 1, no. 1, out/dez, São Paulo, Editora Convívio, 1983. 